\title{
CROSS-NATIONAL COMPARISONS OF PRODUCT DEVELOPMENT IN MANUFACTURING
}

\author{
JOHN E. ETTLIE \\ University of Michigan \\ CARSTEN DREHER \\ Institute for Systems and Innovation Research \\ GEORGE L. KOVACS \\ Hungarian Academy of Sciences \\ LARS TRYGG \\ Chalmers University of Technology
}

\begin{abstract}
In this study we compare product development strategies and practices of five companies in the durable goods industries: one each in the United States (equipment), Sweden (aerospace), Germany (electric motors), Hungary (transportation equipment), and Japan (business machines, cameras/video). In particular, we focus on the concept development phase of new product development and the attend to the aspects of the design process that may be influenced by culture. To the extent that the five cases are representative of their home countries, there appears to be ample variance across cultures to justify further, more extensive research in this arena. A model is presented which differentiates the amount of cultural influence by stage of the product development process in high technology versus low technology industries.
\end{abstract}

New products in both the consumer and durable goods manufacturing industries have enjoyed a resurgence of interest in the last five years due to increasing glohal competition.

Direct all correspondence to: Dr. John E. Ettlie, School of Business, Ann Arbor, MI 48109-1234; Dr. Carsten Dreher. Institute for Systems and Innovation Research, Fraunhofer-Gesellschaft, Breslauer Strasse 48, D-7500 Karlsruhe 1, GERMANY; Dr. George L. Kovacs, Computer and Automation Institute, Hungarian Academy of Sciences, (MTA-SZTAKI), 1111 Budapest, Kende u. 13-17 H-1518 Budapest, P.O. Box 63, HUNGARY; Dr. Lars Trygg, Chalmers University of Technology, S-41296, Goteborg, SWEDEN.

The Journal of High Technology Management Research, Volume 4, Number 2, pages 139-155.

Copyright $\odot 1993$ by JAI Press, Inc.

All rights of reproduction in any form reserved.

ISSN: 1047-8310. 
Successful firms are often thought of as being preoccupied with "products and profits," and it is not surprising that in the United States, for example, $76 \%$ of industrial (versus government or university) research is devoted to the development (versus applied or basic research) of new products, processes and materials (Jain \& Triandis, 1990, p. 3).

In spite of this emphasis on development, relatively little is known about two aspects of the innovation process: the concept development phase of research, development, and engineering and the cross-national differences in approaches to new product development. In this study, we begin to explore this new ground with case study comparisons in five countries.

\section{Idea Generation for Innovation}

Although we know that successful new products come from companies that know their customers' needs, relatively little is known about the early stages of the development cycle when new ideas are born (Ettlie, 1991). Only the rare talent can marry new technology with the customer need that is truly unsatisfied-and often customer needs are not even articulated or consciously realized. It seems clear that creativity, in this regard, is the result of a subtle interaction of personality and joh environment (Hage, 1980; Ettlie \& O'Keefe, 1982; Jain \& Triandis, 1990, p. 56; Jelinek \& Schoonhoven, 1990).

The obvious need to find and keep outstanding talent (Diebold, 1990, p. 173) and the necessity for teams of engineers and other functional or discipline competent professionals to design products and processes of manufacture simultaneously (Clark \& Fujimoto, 1991), appears to be widely recognized. But the notion that one might manage the first stage of product development - before general requirements are dreamed of - using a totally different approach is not well understood. You can't "team" an ideal generation process when a person has not decided to go public with an idea. And you can't "reward" a competent person, if there is no visible product of work associated with a "thought."

A simple case history might help to illustrate this point. At a recent conference on "speed to market" for new products, a story of new product development was presented. After the talk, the presenter was asked if there was anything truly new in the firm's approach to the product's introduction, or if they had done this before. The answer was quite interesting. Instead of using the tried and true method of consistent team leadership and membership, the project had been divided into two parts. There was an "entrepreneurial" phase of the project with one manager, and then the project was turned over to a team and new project manger for the latter stages of development. Not only did this approach turn out to be far better than past firm performances in this product area, it violated all the "street-wise" rules one often follows in the R\&D management game (Boston University, School of Management, March 18-20, 1991).

A second case history is even more revealing on this point. We recently worked with an aerospace firm to document the design process. Among other things, we found that at least $50 \%$ of new product costs are determined before concurrent engineering begins. Concept development accounts for one-half of cost determination in this category of aircraft jet engines.

In short, there seems to be a widespread notion that once we have mastered the team approach to simultaneous engineering, we will automatically be able to get to the market faster with high quality products. We contend that this is only part of the answer. A focus on the pre-simultaneously engineering aspects of product development is needed. 


\section{Cross-National Comparisons}

Cross-national analysis has gradually increased in importance within the broad area of research on technology and innovation management. It recently enjoyed equal billing with topics like micro and macro organizational theory, strategy, and economics (Goodman \& Sproull, 1990). Up until recently, it had been fashionable to use the "power distance," construct from Hofstede's (1980) research at IBM, which includes cultural differences on acceptance of power of boss and subordinate. His other dimensions included uncertainty avoidance, individualism, and masculinity. Now it seems there are alternative constructs and measures (Keller \& Chinta, 1990; Lynn, 1990). In particular it might be desirable to make comparisons on differences in professional orientation (Van Maanen \& Barley, 1984), the use of teams (Ettlie, 1992), and the technological imperative (Markus \& Robey, 1988; Lynn, 1990).

There is preliminary evidence that cultural differences do exist for U.S.-German-Scandinavian comparisons on design practices. German technical training could lead to easier design-manufacturing integration (Lynn, 1990, p. 189). Swedish standardization of design practices could have the same effect (Trygg, 1991). Lee and Wallbaum (1991) report that in 1989, apprenticeship enrollment in the U.S. was 283,352 or about $0.2 \%$ of the 125 million labor force. In Germany, the enrollment for the same period was 1,657,960 or about $6 \%$ of the 30 million labor force. The differences are due in great measure to the role of government support of work force training.

This confirms part of the findings of earlier work reported by Limprecht and Hayes (1982). The management hierarchy in German firms was observed to be consistently staffed with people strong in technical backgrounds and apprenticeship programs made it easier for workers to incorporate manufacturing technologies. The Germans emphasize well-engineered, high quality products, delivered on time with excellent service. German firms tended to accept lower profit margins in order to be more competitive and emphasized long term stability and growth. There is also evidence of U.S.-Japanese differences in managing $\mathrm{R} \& \mathrm{D}$ as well as product development. The Japanese seem to engage in more teamwork earlier in the development cycle (Hull \& Azumi, 1989) and they seem to be able to bring new products to markets faster than their American counterparts (Mansfield, 1988).

There is evidence that there are considerable differences between the U.S., Europe and Japan in employee practices in general, and R\&D human resource policies in particular. Tomlinson, Paulson, Arai, and Briggs (1991) studied 324 businesses in Denmark, Italy, Scotland, the U.S. and Japan. In Japan, the employee was considered the strongest stakeholder, whereas the European and American companies report the customer as the key stakeholder, followed closely by owners. In Japan, unions are partners with management, both in decision-making and productivity improvement. Although this tends not to be true in the U.S. and Europe, there is optimism for change, due in great measure to increased competitive pressures.

During the period 19601987 , the growth rate of new products in Japan was more than double that of the U.S., as was the rate of growth of firm R\&D, and this can be particularly attributed to the Japanese "share plus wage system," (Quinn \& Rivoli, 1991). However, this difference seems to result as much from the internationalization of markets as it does from some inherent advantage of the Japanese compensation system to promote innovation. What is more, there appears to be an argument that trying to adopt just one aspect of 
another culture's compensation and incentive system (e.g., life-time employment) may introduce as many problems as it solves.

However, it is not always clear why these differences exist or the extent to which such variance is culture determined. Hagerty and Hoffman (1990) found that the outcomes of comprehensive planning varied in Anglo, Germanic, and Nordic countries. Anglo firms with better planning had greater return on sales while Germanic firms with better plans had greater return on assets. Nordic firms had greater sales growth when they were comprehensive planners. In another study, Schneider and DeMyer (1991) found differences in interpretation of risk by strategic planners across cultures.

It seems highly likely that firms within countries participating in durable goods manufacturing will differ in their approach to the concept development phase of new product and process launch. They obviously differ in the emphasis and value placed on various aspects of the design process, but the question is whether this variance is detectable using the methodologies currently available to study this phenomenon, and whether or not it makes a difference in performance. For example, German manufacturing is likely to have more technical managers, and Eastern and Central European countries have had less access to computer-aided design technologies. Both circumstances are likely to have consequences in design approach.

It also seems clear that cross-national differences are often a matter of philosophy and perceptions as much as actual measurable practices. Cole (1990) has made extensive comparisons between the U.S. and Japanese automobile industry, for example, and finds that the Japanese not only incorporate new technology in their continuous improvement programs, but also have very sensitive perceptions of very small quality differences. In the U.S., technology adoption and development are often done in parallel to manufacturing productivity enhancement and product development. Further, Cole (1990) found that the differences in perception of measurable outcomes like 1.6 defects per vehicle versus 1.0 defects per vehicle are quite important to the Japanese but perceived as very subtle and, therefore, less important in the U.S.

\section{METHODOLOGY}

Lynn (1990) reviewed the state-of-the-art of research on technology management for crossnational studies and recommended comparative case studies because of the nascent stage of development of this research area. Eisenliardt (1989) concluded that the case study approach could be used as a theory-building exercise. This is the approach that was taken in this study.

With the collaboration of colleagues, five firms were selected from short lists of established durable goods manufacturers well-known and accessible to the research team. One case from each of five of the major economic alliances or regions of the world was nominated: the U.S. to represent North America; Sweden to represent EFTA; Germany to represent the ECC; Hungary to represent the old COMACON trading bloc and Japan to represent the far east. Only six firms had to be asked to generate five cases.

In all but one case, two colleagues conducted the interview of one primary respondent in the firm. In one case (Hungary), two secondary respondents also participated in the interview. In the Japanese case, the interview schedule was used as a mailed questionnaire. Follow up faxes were used for clarification. The Japanese respondent was eventually interviewed in Japan for the project and provided additional data. The American researcher 
visited four of the five firms. In each country (except Japan, as noted), one colleague who's first language was that of the host nation also helped conduct the interview. In the Hungarian case, the collaborator also translated much of the proceedings. In each case the initial contact with the firm was made by the host country colleague and then the interview schedule and other materials were shared before scheduling appointments requesting cooperation. Confidentiality was guaranteed in all cases.

Wherever possible, we used "visual data" as cues for respondents to describe their design process (Meyer, 1991). That is, in the case of describing their technology to support design and their barriers to concurrent engineering, outline materials were handed to the person to reflect on and help structure responses. Respondents were all new product, new process, or R\&D managers, and intimate with new products in their firm.

Although this was an exploratory study, several differences between these firms were expected to show up in both economic and accounting type measures of product and process development as well as general approaches to design. These differences are highlighted below. On the other hand, all of these companies have been operating for a long time and would be considered successful enterprises with a bright future by most standards.

\section{RESULTS}

The preliminary comparisons of these five durable goods producers was made in three general categories.

1. They were compared on general, background characteristics (e.g., organizational size).

2. They were compared on their approach to concept development and idea generation for projects.

3. And finally, they are compared on their overall capabilities and practices of development as well as design-manufacturing integration (Ettlie \& Stoll, 1990).

In Table 1, the responses concerning changes in the process of product development are summarized. In all five companies, representatives said they had a program to upgrade current product development practice. Four of five said that quality and time to market were part of this program. The Hungarian, Swedish and American firms said suppliers were part of the program. Hungary and Sweden were modernizing their plants. The German and Swedish firms were reorganizing. The German firm reported the least number of areas (most focused?) of program change at three; Hungary was next with five. The Japanese firm reported only one reason: patents. Perhaps, this was due to the fact that the respondent was a senior, high-ranking R\&D manager.

The results of the other comparisons appear in the summary presented in Table 2 below. Information in this table is divided into three categories:

1. background information;

2. concept development information; and

3. design-manufacturing integration.

All of these firms are relatively large and they all supply industrial or consumer markets in durable goods industries. The Swedish, Japanese, and American firms are publicly held, while the German firm is still owned by members of the founding family. The Hungarian 


\section{TABLE 1 \\ Cross-national Comparisons: Changing The Process Of Product Development ${ }^{a}(n=5)$}

\begin{tabular}{|c|c|c|c|c|c|}
\hline \multirow[b]{2}{*}{ Areas of Program Change } & \multicolumn{5}{|c|}{ Country and Case } \\
\hline & $\begin{array}{c}\text { Germany } \\
\text { (electric } \\
\text { motors) }\end{array}$ & $\begin{array}{c}\text { Hungary } \\
\text { (Trans. } \\
\text { Equip.) }\end{array}$ & $\begin{array}{c}\text { Sweden } \\
\text { (Aerospace) }\end{array}$ & $\begin{array}{c}\text { U.S. } \\
\text { (Plastics } \\
\text { Equip.) }\end{array}$ & $\begin{array}{c}\text { Japan } \\
\text { (Business } \\
\text { Machines) }\end{array}$ \\
\hline Quality & $\sqrt{ }$ & $\sqrt{ }$ & & $\sqrt{ }$ & \\
\hline Time to Market & $\sqrt{ }$ & $\sqrt{ }$ & $\sqrt{ }$ & $\sqrt{ }$ & \\
\hline Suppliers & & $\sqrt{ }$ & $\sqrt{ }$ & $\sqrt{ }$ & \\
\hline Plant Modernization & & & $\sqrt{ }$ & & \\
\hline \multicolumn{6}{|l|}{ Other: (please name) } \\
\hline Reorganization & $\sqrt{ }$ & & $\sqrt{ }$ & & \\
\hline "Getting up-to-date" & & $\sqrt{ }$ & & & \\
\hline Education & & & $\sqrt{ }$ & & \\
\hline "Machine Marketability" & & & & $\sqrt{ }$ & \\
\hline Patents & - & - & - & - & $\underline{V}$ \\
\hline Program Area Totals & 3 & 5 & 6 & 4 & 1 \\
\hline
\end{tabular}

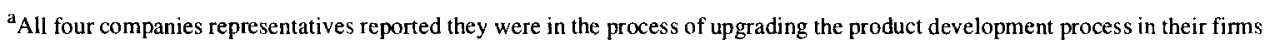

firm is most unique in its ownership. It is owned $30 \%$ by a Russian Monetary Group, $50 \%$ by the Hungarian government and $20 \%$ of its stock are about to be traded on the public market.

\section{Product Life Cycles and R\&D}

The current product life cycle of these firms varies from about 25 years for the Swedish aerospace components supplier to seven years for the American plastics equipment OEM. When compared to the projected life cycle of new products, we get some, but not all, predictable results (c.f., Ettlie \& Warner, 1991) for the German and U.S. cases: there is an anticipation in these two durable goods manufacturers that their product's future life cycle will be shorter. In the case of the German firm, the expectation is that it will change from the current 10 years to 5-10 years. In the case of the American firm, current life cycles of seven years are expected to become five years.

In Hungarian and Swedish firms-both in transportation industries (ground mass transit and aerospace respectively) - we see a different pattern. The Hungarian company expected the life cycle of its product to increase from 7-10 years to 15 years because of increased durability of products and extended warranty guarantees. In the case of the Swedish aerospace division, product life cycles are not expected to change and are the longest among these durable goods manufacturers at 20-30 years. In the Japanese consumer products firm, product life-cycle was likely to increase from three to five years.

The Hungarian firm exports the greatest amount of product (in excess of 90\%). Next came the Japanese firm at $70 \%$, then the German firm at $60 \%$ export and then the Swedish firm with over $50 \%$ shipments out-of-country. The American firm was lowest with $10 \%$ exported product. 


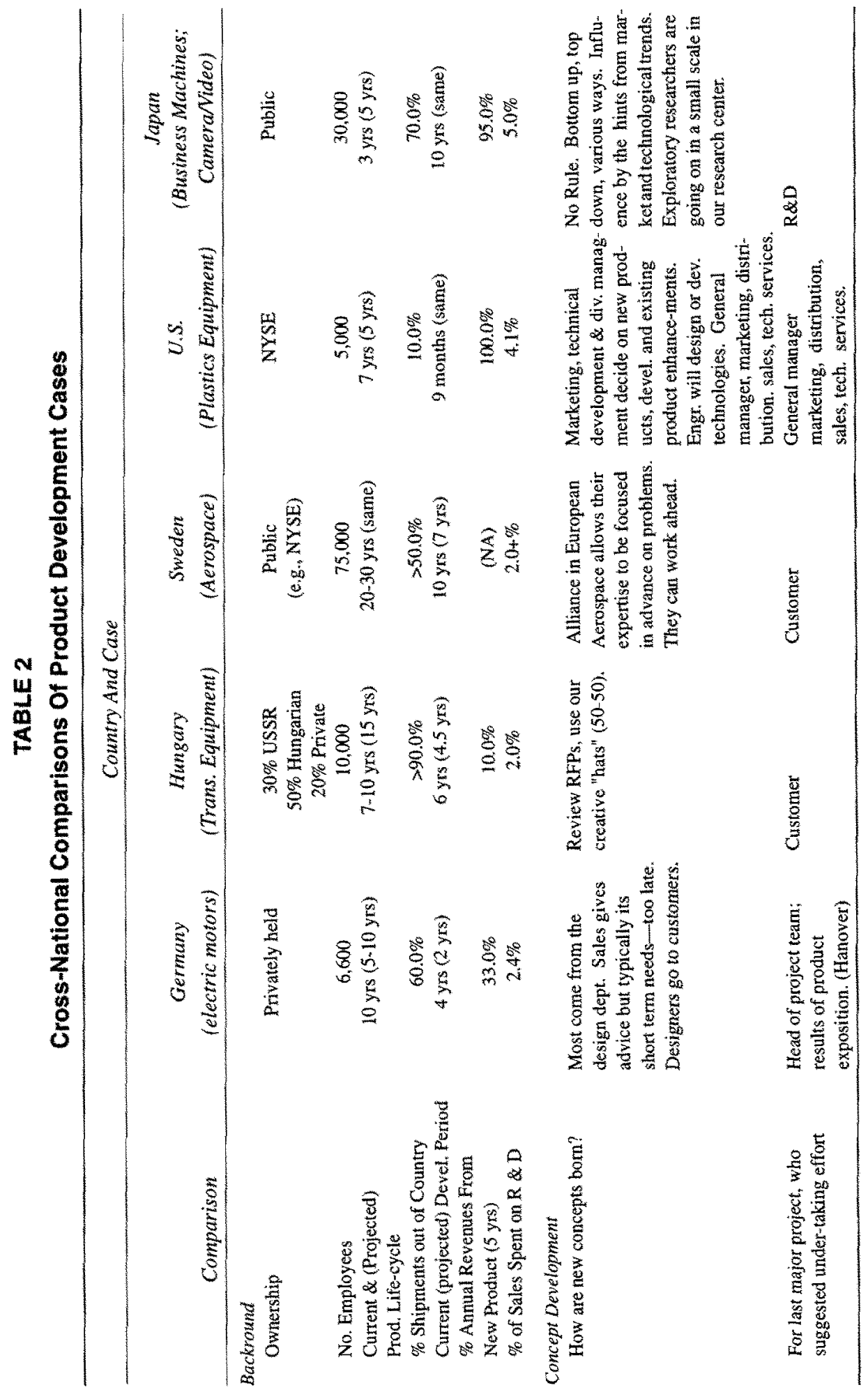




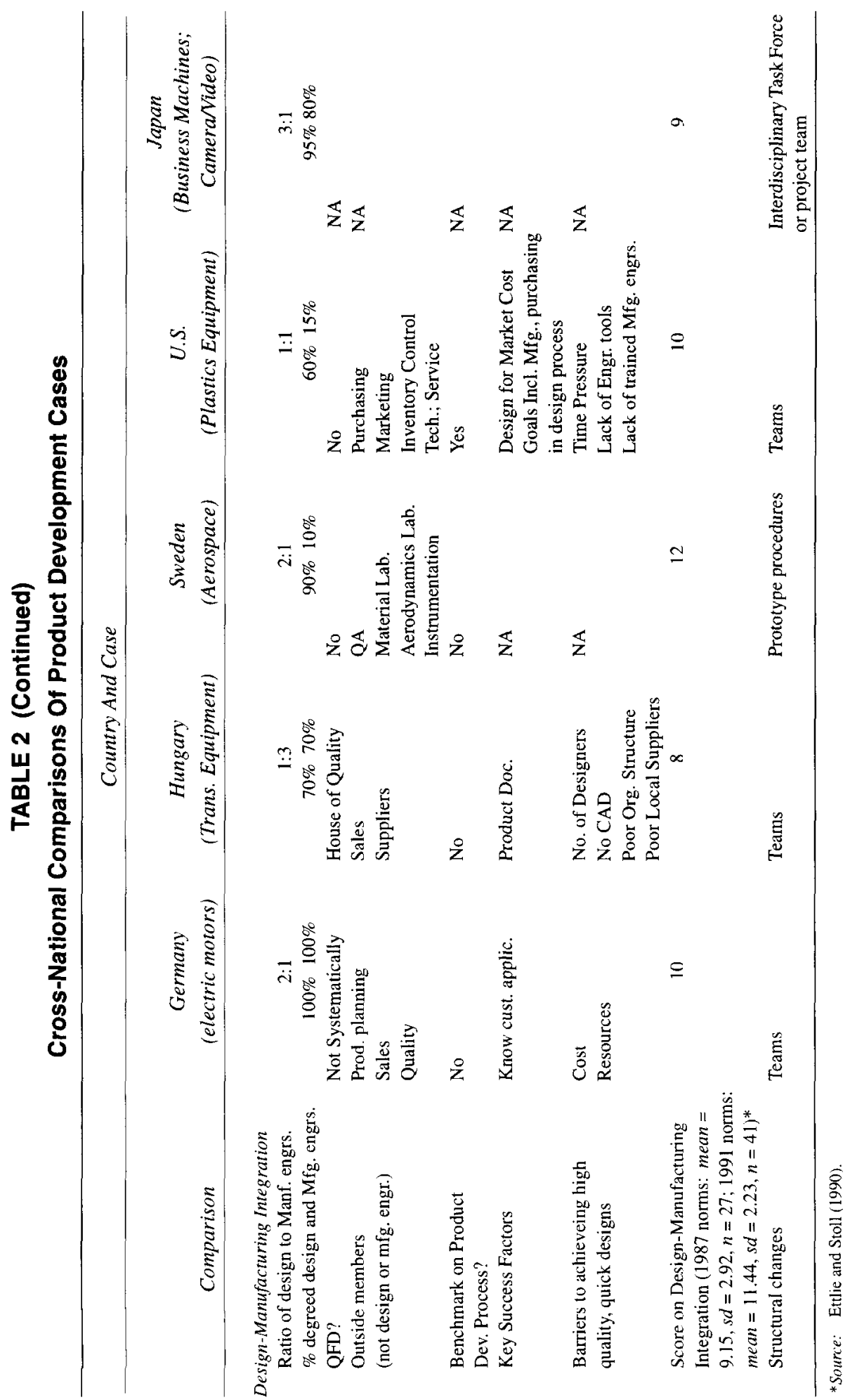


Current and projected development periods summarized in Table 2, and with two exceptions, all follow a typical pattern (Ettlie \& Warner, 1991) - they are all getting shorter. The German electric motor company currently takes four years to develop a new product but their goal is to reduce this by $50 \%$ to two years. The Hungarian company takes six years to develop a new product but wants to shorten this to 4.5 years-a $25 \%$ reduction. Even though life-cycles are expected to be constant in the foreseeable future for the Swedish aerospace company, they want to reduce development time from 10 years to 7 years for a new product-a $30 \%$ reduction.

The American and Japanese firms seem to be satisfied with their current development period which was reported to be nine months and 10 years, respectively. However, the Japanese respondent also noted in a followup interview that the $\mathbf{1 0}$ years (see Note in Table 2) refers to basic research to new business, not existing technology. Further, development time is likely to increase because of environment (ecological) concerns.

The American firm has the most favorable ratio of product life cycle to development period (seven years divided by 0.75 years $=9.33$ years). That is, this company returns 9.33 years of product life for every year invested in new product development. This firm also has the highest percentage annual revenues from new products $(100 \%)$ and spends the next-to-the most (behind the Japanese firm), as a percentage of revenues, on R\&D: $4.1 \%$. It seems clear that the strategy of the American plastics equipment firm is to emphasize R\&D supported new products and the revitalization of their design practices reported during the interview substantiate this.

The ratio of product life cycle to development period is 2.5 years for both the German firm ( 10 years divided by four years) and the Swedish aerospace division ( 25 years divided by 10 years). The Hungarian firm returns 1.4 years of life cycle for every year devoted to new product development ( 8.5 years divided by six years). All three of these companies spend about the same amount on R\&D as a percentage of sales: approximately $2 \%$. The Japanese firm was an outlier in both respects. It spent the most on R\&D ( $5 \%$ of sales) and only got one-third of a year back in life cycle (three years) for every year spent developing product ( 10 years). Since it was the only consumer durable in the sample, this does not seem surprising. They sought to increase (by two yrs) their product life cycle, which may be an important finding.

\section{Concept Development and New Ideas}

Perhaps one of the most interesting and important sections of the interviews was devoted to investigating how new ideas and concepts are born in these four firms. All had a unique approach to new product midwifery. In the German company, most ideas come from the design department, which would be expected from the culture's technical and organizational traditions. The sales department gives advice and feedback from customers, but the opinion was that these are immediate, short-term customer needs only. In order to anticipate future, long-term customer needs, more has to be done. Designers typically visit customers or interact with potential buyers at trade shows and fairs. The technical project leader provides vision and direction in this German company.

In the Hungarian mass transit vehicle company, the concept development process is driven by RFPs (requests for proposals or quotes), usually from local municipalities. But this is truly a global company, supplying product to many U.S. major cities and many other 
countries around the world, so there is great variance in these requests. There appears to be a 50-50 play between understanding these RFPs and the "creative hats" of design teams.

The Swedish aerospace company supplies components to the European consortium which builds the Ariane 5 launcher and the Vulcain engine. The cooperative arrangement between funding governments in this consortium provides a very unique context for product development in this company. Since there is a sharing of tasks among countries, the firm with the greatest expertise will be contracted to supply a component. With reasonable certainty, companies in the consortium can rely on future contracts and can "work ahead" in the development cycle. This could reduce technological uncertainty by providing the needed time to resolve technical issues and stabilize human resource allocation.

The American plastics equipment manufacturer appears to stress a team approach to concept development. Both marketing and technical representatives influence which ideas are reviewed. Division management then reviews these proposals, or even suggests ideas on occasion regardless of type of change proposed: new products, product enhancements and development work. Technical services and distribution have a role in documenting customer need information along with distribution. Engineering has the responsibility of seeing that technological development keeps pace and is timed with this process of idea generation. The Japanese firm seemed nearly identical in its approach-a mix of top down . bottom up and marketing-R\&D "hints".

\section{Design-Manufacturing Integration}

Considerable attention has been focused on concurrent engineering during the last five years (e.g., Nevins \& Whitney, 1989). Some base-line data on organizational policy and structural practices used to facilitate coordination between functions and disciplines is available (e.g., Ettlie \& Stoll, 1990). Questions from earlier survey work were used to gauge these five comparative cases.

The ratio of design to manufacturing engineers varied considerably across these companies. The most extreme ratio was for the Japanese company: three (product) to one (manufacturing engineers). In German firm, the ratio was 2:1-the same as the Swedish aerospace division. The ratio in the American firm was 1:1. In the Hungarian firm, there were more manufacturing engineers than designers where the ratio was 1:3. In the 1987 base-line data (Ettlie \& Stoll, 1990), the average ratio in U.S. firms was 2.9:1. In the 1991 survey of 43 American durable goods manufacturers, this ratio was 4.7:1 (Ettlie \& Warner, 1991). The Japanese firm most closely matched the U.S. averages from previous survey work.

The proportion of degreed design and manufacturing engineers was most even in the German firm at $100 \%$ and $100 \%$ respectively. In fact, the question really has little meaning in the German company - all engineers are degreed, naturally. Otherwise they could not be called engineers. The Japanese firm was next in order with an estimated ratio of $95 \%$ degreed design engineers to $80 \%$ degreed manufacturing engineers.

In Hungary, there is a similar pattern, although parity is achieved at a lower absolute level: $70 \%$ degreed design engineers and 70\% degreed manufacturing engineers. This seems consistent with the cultural history of Hungary and the influence of German practices on Hungarian industry during modern times.

In the Swedish aerospace company there is a substantial gap in degreed engineers. Although $90 \%$ of design engineers are degreed, only $10 \%$ of manufacturing engineers have 
a degree. In the American firm, $60 \%$ of design engineers were degreed versus $15 \%$ of manufacturing engineers. In the recent survey of U.S. practices (Ettlie \& Warner, 1991) median levels for degreed design and manufacturing engineers were $90 \%$ and $60 \%$ respectively.

In the recent survey of design practices of 43 American companies (Ettlie \& Warner, 1991), it was found that disciplines and functions most often represented on the design team outside of engineering continue (from 1987) to be marketing and quality. There is an echo in this finding from these five companies. In the German firm, production planning, sales and quality are the three outside functions on the design team. In Hungary, sales and suppliers are represented. In the Swedish firm, quality assurances (QA), material and aerodynamics laboratories, as well as instrumentation are represented. In the U.S. company, purchasing, marketing, inventory and technical services are included in the focused design effort. Only the Hungarian firm reported using Quality Function Deployment (QFD)"House of Quality."

The Swedish and American firms seem to be the most diverse in there breadth of disciplines and functions included in the design process. However, only the American firm reports doing any benchmarking for design and development practices. About half of the U.S. firms surveyed recently did this type of benchmarking (Ettlie \& Warner, 1991). The Japanese had the most missing data and said that "concurrent engineering" had no meaning to them. Like other reports from Japan, it is disciplines organized into project or product departments that is most descriptive (Fruin, 1991).

Key success factors for design are also consistent with earlier findings, when reported. The German firm and American firm put the customer first and get ideas for new products from customers. The Hungarian firm, responding to RFPs, felt that production documentation was most important. The Swedish firm did not answer this question. Again, the Japanese representative did not comment on this question.

Barriers to achieving high quality designs, quickly, were also reported by four companies, but integration of functions did not appear in any of the answers, which was unexpected (c.f., Ettlie \& Warner, 1991). The German, Hungarian, and American companies all emphasized resource constraints as the biggest barrier to achieving design goals. The Japanese firm mentioned resources as an issue elsewhere. In the Hungarian case, this included the absence of successful installation of a CAD system company-wide. Both the American and Hungarian firm complained about the lack of engineering tools and lack of trained engineers. Like other U.S. firms surveyed recently (Ettlie \& Warner, 1991), the American plastics firm listed "time pressurcs" as the biggest barrier to product development. Cycle time reduction was thought to be a strategic opportunity in manufacturing, not a barrier. Rethinking this issue is clearly in order. Cycle time reduction in R\&D, product development and design is not as obvious as it might seem.

Structural adaptations that were reported by four of these five firms were quite expected. The German, Hungarian, Japanese and American firms all reported using teams to facilitate design-manufacturing integration. The Swedish firm reported adopting new prototyping procedures.

In previous surveys in the U.S., a set of five design-manufacturing integrating practices have been monitored (Ettlie \& Stoll 1990; Ettlie \& Warner, 1991). These include the use of outside training and development in design-for-manufacturing techniques, the adoption of manufacturing sign-off at design review stages, the installation of new structures (e.g., teams) to help coordination, job rotation between functions, and mobility between functions. We score the adoption of these practices as follows: "yes" $=3$; "no" $=1$, and "in- 
process of adoption" $=2$. The minimum score possible is five and the maximum possible is $\mathbf{1 5}$. The scores for these four cases and the norms (means and standard deviations) from two previous surveys are presented in Table 2.

The Swedish aerospace company reported adopting design-manufacturing integration practices at the highest level of these four cases. With a score of 12 , they were above the other cases and above the mean score in the U.S. survey from 1987 (9.15) as well as the U.S. mean in 1991 (11.44). The German and American firms were tied at a score of 10 each which means they adopted three of the five practices, and were in process on a fourth. The Japanese firm used two of these methods (sign-off and structure-teams) and scored a nine, but also said terms like "concurrent engineering" have little meaning in the company. This suggests that other means or the dominance of teams takes the place of this index. The Hungarian firm, which also reported structural problems as a barrier to good design practices, scored lowest with an eight on this measure. Given that the Hungarian firm had limits to reinvestment of revenues for so many years, it is not surprising that they report difficulties in achieving design goals, but they are aware of the challenge.

\section{THE CULTURAL WAY TO DESIGN}

Is there a "German Way" to design? Is there a Hungarian Way ("Goulash Design")? Is there a typically Swedish approach to Design? Is there an American or Japanese way? We asked this question and all the answers were all the same-No, of course not. No attempt was made in this exploratory study to determine whether industry differences swamp cultural differences or if company culture is more important than competitive environment, and so on. But one gets the impression that the seeds of a comparative base needed to answer the question of which aspects of product development are more influenced by ambient culture are present in these cases and provide guidance for future research. The Japanese respondent added that his company is not typical of Japan, either.

Some illustrations provide insight into this question. It seems beyond chance that the German firm has parity in degreed design and manufacturing engineers at the $100 \%$ level. It is what one expects in Germany and of the stereotypical German approach to technical problems-thorough, painstaking, and with high technical standards. Given the historical influence of Germany on Hungary, it is not surprising to see parity in the latter, but at a diminished (resource constrained) level in engineering degrees ( $70 \%$ and $70 \%$ respectively). The Japanese firm was conparable will a $95 \%-80 \%$ split. Since product development is, in part, a very technical activity, one would expect that this type of measure might capture these culture-dependent aspects of the design process. On the other hand, the Hungarians are known for their entrepreneurial approach to business, so it is not surprising that they are the only ones to actually mention emphasizing a "creative" approach to product development.

The dominance of design engineering in Swedish firm might be attributed to industry factors, but perhaps there is more to this. In some respects, the Swedish and German approach, if there is such a thing, are similar: they both have similar ratios of design to manufacturing enginecrs, but the Swedish firm has many more degreed designers ( $90 \%$ vs. $10 \%)$.

\section{AN EMERGENT MODEL OF CULTURAL INFLUENCE ON DESIGN}

In a recent interview with a manufacturing engineering manager at a large American aerospace firm, it was learned that design department dominance is typical in this industry. 
Manufacturing engineers have much less to say about design, even in very successful aerospace companies, than design engineers. This suggests that the design department in the Swedish firm has more freedom than in the other firms of this small case sample, and perhaps this is the way it is preferred in Sweden. The Swedish and Japanese cases are also unique in their dependence, by explicit mention, on $R \& D$ laboratory work in developing and testing technology. The fact that this Swedish aerospace division represents only a small fraction of business activity of that corporation appears to have little relevance to design practice and product development. Not coincidently, the Japanese firm reported the highest R\&D intensity ( $5 \%$, at least, of sales).

Perhaps the most encouraging finding of these five case comparisons is the unique approach used for concept development and generation of ideas. This suggests that the early phases of design which, heretofore, have been least structured, are most subject to cultural differences. Hellwig (1992) reports that for "product genesis," or the "evolution of an idea into a manufactured and marketed product" (p. 77), there are considerable differences between U.S. and Japanese firms. American firms consider all aspects of this process proprietary, and in the case of high technology industries, applied research and basic research are also considered proprietary. American consortia rarely go beyond basic research and often restrict foreign participation. Cooperative projects in Japan are often extended through prototyping and foreign firms are often invited to join. Lack of language skills by non-Japanese participants is not necessarily a barrier to cooperation with scientists or technology managers. Furthermore, there appears to be a convergence between the U.S. and Japan in mutual emulation of approaches. Japan is moving away from large markets (e.g., consumer electronics) and towards U.S. strengths in small, specialty markets (e.g., medical instruments). American firms are joining with Japanese firms in large market areas (like automobiles). Japanese efforts to learn from the U.S. are often initiated by their government programs like MITI (Ministry of International Trade and Industry).

Osborn and Baughn (1993) note in their review that the increasing pace of technological change globally has lead to the simultaneous commercialization of new products in such high technology industries as aerospace, and that industry boundaries become blurred when technologies contributing to new products are merged (e.g., pharmaceuticals and biotechnology; computers and telecommunications). Countries that emphasize high technology industries avoid direct competition with developing nations, as well. Since global technology alliances are prone to failure (Osborn \& Baughn, 1993), examination of high versus low technology industries across nations and cultures scem logical. Amcrican firm direct investigation of Japanese R\&D and investment in U.S. endowed research chairs at University by the Japanese are trends which confirm this proposition (Moffat, 1991).

Therefore, the dimension that seems to be needed here in order to keep industry and technology differences in mind, is the high-tech, low-tech distinction. Gomez-Mejia (1991) distinguishes high technology firms from traditional companies using 13 dimensions. These include characterizing high technology firms as incorporating cutting edge technology in products, shorter product life-cycles, typical of the electronics, computer, and chcmical industries, with a high rate of innovation, relatively high R\&D intensity (more than 6-10\% of sales spent on R\&D), a high proportion of R\&D employees with high personnel turnover in the technical ranks, often with a high rate of growth but greater mortality, and with higher, but more variable profits.

Although Gordon (1991) argues convincingly that industry is an important determinant of organizational culture, it can also be argued that industries cluster in at least these two 
categories of high and low technology. Doz (1986) studied multinational firms and found that technology driven companies were more likely to use economic-integration as a strategy versus political responsiveness. These companies tend to be global and are less likely to be influenced by local conditions. There are some exceptions, of course.

There are a number of practical, methodological, and theoretical issues that are raised by the distinction between high and low tech industrial activity. For practical reasons, the relative scarcity of such engineering skills as software development, may be a barrier to both firm and industry growth and competitiveness. Some industries and countries are at a relative disadvantage in this regard.

The preferred methodology of cross-national research is also influenced by the dynamics of industries and the clustering of same. That is, if one were to choose groups of industries without empirically validating that they go together, or pick clusters of countries without establishing that certain fundamental characteristics of their populations were related (e.g., common history or language), there would be questions of interpretation. In other words, one has to be careful when establishing a percent in research that cannot be well understood or replicated.

Finally, the theory of innovation processes that included new product development, which takes into account the idea that culture can be represented by nation clusters and that industries cluster in meaningful ways is challenging to develop and begging to be tested. One of the reasons for this challenge is uniquely felt in the United States and North America. What we are often modeling here is the relative difference between clusters like culture and high technology rather than which dimension to include. North America, like Europe, persists as a very pluristic cultural domain with a multitude of industry types. Japan now shares center stage with at least four, and more accurately six, newly industrialized countries in the Far East. Therefore, we have what is often called the 'within group' versus the 'between group variance issue. Add a third group (degree of technology churning- high versus low tech) and it creates some theoretical challenges, indeed.

In high-tech industries, it could be argued that early stages of product development--like the preconcept and concept development stages-are less likely to show cultural influences because science dominates (Osborn, 1992, personal communication). Although scientific work communities may act differently in the U.S. and Japan (e.g., Traweek, 1988), when basic research is an integrated part of corporate product development, it is hypothesized that cultures converge into similar forms of work routines. Moreover, since thinking preferences appear to be as much a function of interests as well as culture (Talbot \& Geyer, 1991), industry and strategy may actually "self select" the people attracted to a company. This may also partially explain the resulting patterns here. In low-technology industries, like two of the cases (Hungarian buses and plastics producing equipment in the U.S.) included in the present cross-national comparisons, the early stages of product development which are not science driven, are more likely to be influenced by culture. Product design and process design in both situations are likely to be less and more influenced by culture, respectively, because process design is downstream in the process and more influenced by plant conditions. Product design is driven by customer requirements and should be less influenced by the culture of the provider. This is summarized as a model for testing in Figure 1 below.

A broad survey of cultural differences in product development appears to be one alternative methodology to follow-up on these case studies. If industry makes a difference in the pattern of cultural influences, a sample of sufficient magnitude to make these comparisons would be desirable. Resolving the clustering and measurement issues for high and 


\section{FIGURE 1 \\ Cultural Influences on the Product Development Process}

\begin{tabular}{|c|c|c|c|c|}
\hline & Preconcept & $\begin{array}{l}\text { Concept } \\
\text { Development }\end{array}$ & $\begin{array}{l}\text { Product } \\
\text { Design }\end{array}$ & $\begin{array}{l}\text { Process } \\
\text { Design }\end{array}$ \\
\hline High Tech & Low & Medium & Low & High \\
\hline Low Tech & High & High & Low & High \\
\hline
\end{tabular}

low technology industries will be one of the challenges of this research. The focus on early concept development and culture appears to warrant further, more extensive research.

There are a number of alternative paths that this research stream might follow. For example, one might take candidate countries to sample within each major trading group (e.g., Japan, the U.S. or Germany, or Korea, Canada, and Italy) to compare. There will, of course, always be tradeoffs, between coverage and the cost of the research effort. Another strategy would be to compare several countries within two groups (e.g., Korea, Hong Kong, Japan and Germany, Spain, and Belgium). Finally, any two countries between groups could be compared (e.g., Japan and Germany). However, comparing, say, the U.S. and Canada, or Germany and France, or Japan and Korea, would not make much sense for this line of research.

Even as one expands beyond the case study approach to this cross-national research stream, there will be opportunities for the recognition of theoretical, methodological, or practical emergent trends. If, for example, the world makes good on cross-national personnel movement; if we develop reliable methods of culture-free self-report or archival analysis; and if we find that a post-cold war world is more similar than different, then the economic and environment preservation issues that could respond to technological innovation may finally surpass political and racial issues that have often dominated intercultural relationships.

\section{ACKNOWLEDGEMENTS}

Work in this area was supported in part by the Center for International Business Education, University of Michigan and the Japan Tcchnology Management Program. Wc wish to thank the organizational members in the U.S., Swedish, Japanese, German and Hungarian firms that participated in this project for their generous sharing of information and time. We want to thank Professor Toyohiro Kono for helping to locate the Japanese Company that participated in this study.

\section{REFERENCES}

Boston University, School of Management. (1991) . Executive summary of the 1990 international manufacturing futures survey. Boston, MA. Author

Clark, K.B., \& Fujimoto, T. (1991). Product development performance. Boston: Harvard Business School Press.

Cole, R. (1990). U.S. quality improvement in the auto industry: Close but no cigar. California Management Review (Summer), 71-85. 
Diebold, J. (1990). The innovators. New York: Truman Talley Books.

Doz, Y.L. (1986). Strategic management in multinational companies. Oxford: Pergamon Press.

Eisenhardt, K.M. (1989). Building theories from case study research. Academy of Management Review, 14(4), 532-550.

Ettlie, J.E. (1992). Concept development effort in manufacturing. In G. Susman (Ed.), Integrating design and manufacturing for competitive advantage (pp. 103-122). Oxford: Oxford Press.

Ettlie, J.E., O'Keefe, R.D. (1982). Innovative attitudes, intentions, and behaviors in organizations. Journal of Management Studies, 19(2), 153-162.

Ettlie, J.E., \& Stoll, H.W. (1990). Managing the design-manufacturing process. New York, NY: McGraw-Hill.

Ettlie, J.E., \& Warner, M.D. (1991). Managing design systems in manufacturing. University of Michigan, Ann Arbor, MI: University of Michigan Press.

Gomez-Mejia, L.R. (1991). Features distinguishing high technology from traditional firms. Presented at the National Academy of Management Meeting, Technology and Innovation Management Ph.D. Consortium, Miami, Florida.

Goodman, P.S., Sproull, L.S. (1990). Technology and Organizations. San Francisco: Jossey-Bass.

Gordon, G.G. (1991). Industry determinants of organizational culture. Academy of Management Review, 16(2), 396-415.

Hagarty, W.H., \& Hoffman, R.C. (1990). The relationship between strategic planning and performance among three cultures. Proceedings, Academy of Management, 106-110.

Hage, J. (1980). Theories of organizations. New York: Wiley Interscience.

Hellwig, H. (1992). Differences in competitive strategies between the United States and Japan. IEEE Transactions on Engineering Management, 39(1), 77-78.

Hofstede, G. (1980). Culture's consequences: National differences in thinking and organizing. Newberry Park, CA.: Sage.

Hull, F.M., \& Azumi, K. (1989). Teamwork in Japanese and U.S. labs. Research \& Technology Management (November/December), 21-26.

Jain, R.K., \& Triandis, H.C. (1990). Management of R\&D organizations. New York: Wiley.

Jelinek, M., \& Schoonhoven, K. (1990). Innovation marathon. London: Basil Blackwell.

Keller, R.T., \& Chinta, R.R. (1990). International technology transfer: Strategies for success. Academy of Management Executive (May), 4(4), 33-43.

Lee, J. A., \& Wallbaum, N. (1991). Apprenticeship training: The U.S. versus West Germany. Operations Management Review, 8(3/4), 19-25.

Limprecht, J.A., \& Hayes, R.H. (1982). Germany's world-class manufacturers. Harvard Business Review (November/December), 137-145.

Lynn, L.H. (1990). Technology and organizations: Cross-national analysis. In P.S. Goodman \& L.S. Sproul (Eds.). Technology and organizations (pp. 174-199). San Francisco: Jossey-Bass.

Mansfield, E. (1988). The speed and cost of industrial innovation in Japan and the United States: External vs. internal technology. Management Science, 34(October), $1158 \mathrm{ff}$.

Markus, M.L., \& Robey, D. (1988). Information technology and organizational Change: Causal structure in theory and research. Management Science, 34(May), 583-598.

Meyer, A.D. (1991). Visual data in organizational research. Management Science, 2(May), 218-236.

Moffat, S. (1991). Picking Japan's research brains. Fortune (March, 25), 84-96.

Nevins, J.L, \& Whitney, D.E. (Eds). (1989). Concurrent design of products and processes. New York: McGraw-Hill.

Osborn, R., \& Baughn, C.C. (1993). Societal considerations in global technological development of economic institutions: The role of strategic alliances. In Research in the Sociology of Organization, Vol. 2, pp. 113-150.

Quinn, D.P., \& Rivoli, P. (1991). The effects of American- and Japanese-style employment and compensation practices on innovation. Organization Science, 2(November), 323-341.

Schneider, S.C., \& De Meyer, A. (1991). Interpreting and responding to strategic issues: The impact of national culture. Strategic Management Journal, 12, 307-320. 
Talbot, R.P., \& Geyer, R.L. (1991). Comparing cross-cultural thinking preferences. National Production Review (Spring), 181-193.

Tomlinson, W.H., Paulson, S.K., Arai, J., \& Briggs, D.H. (1991). Company identity, quality improvement, and labor-management relations in Danish, Italian, Japanese, Scottish, and U.S. Firms. National Productivity Review (Spring), 129-144.

Traweek, S. (1988). Beamtimes and Lifetimes: An Ethnography of the High Energy Physics Community in Japan and the U.S. Boston, MA: Harvard University Press.

Trygg, L. (1991). Engineering design: Some aspects of product development efficiency. Department of Industrial Management and Economics, Goteborg, Sweden: Chalmers University of Technology.

Van Maanen, J., \& Barley, S.R. (1984). Occupational communities: Culture and control in organizations. In Research in Organizational Behavior (pp. 287-365). Greenwich: JAI Press. 